\title{
Death of a classified worker probably caused by overexposure to $\gamma$ radiation
}

D C Lloyd, A A Edwards, E J Fitzsimons, C D Evans, R Railton, P Jeffrey, T G Williams, A D White, M Ikeya, $H$ Sumitomo

National Radiological Protection Board D C Lloyd

A A Edwards

Monklands Hospital, Airdrie

E J Fitzsimons

C D Evans

$R$ Railton

Field Operations

Division Health and

Safety Executive,

Glasgow

$P$ Jeffery

T G Williams

University Hospital,

Cardiff

A D White

University of Osaka

$M$ Ikeya

H Sumitomo

Correspondence to:

D C Lloyd, National

Radiological Protection

Board, Chilton, Didcot,

Oxfordshire OX11 0RQ.

Accepted 15 July 1994

\begin{abstract}
This paper describes the case of an industrial radiographer who was seriously overexposed to $\gamma$ radiation. The exact circumstances of his exposure were not established but it was concluded that he was repeatedly irradiated probably to a total average whole body dose of at least 10 Gy over several years. Also, a much larger dose to a hand required its partial amputation. He developed myelodysplasia, which progressed to acute myeloid leukaemia from which he died. Karyotypic examination of the leukaemic blasts showed changes very similar to those associated with secondary leukaemia that may develop after radio or chemotherapy. The paper describes his medical case history, the investigation of his workplace, and the attempts to estimate his radiation dose by chromosomal analysis of blood lymphocytes and electron spin resonance of dental enamel and bone.
\end{abstract}

(Occup Environ Med 1994;51:713-718)

Keywords: industrial radiographer, $\gamma$ radiation, overexposure

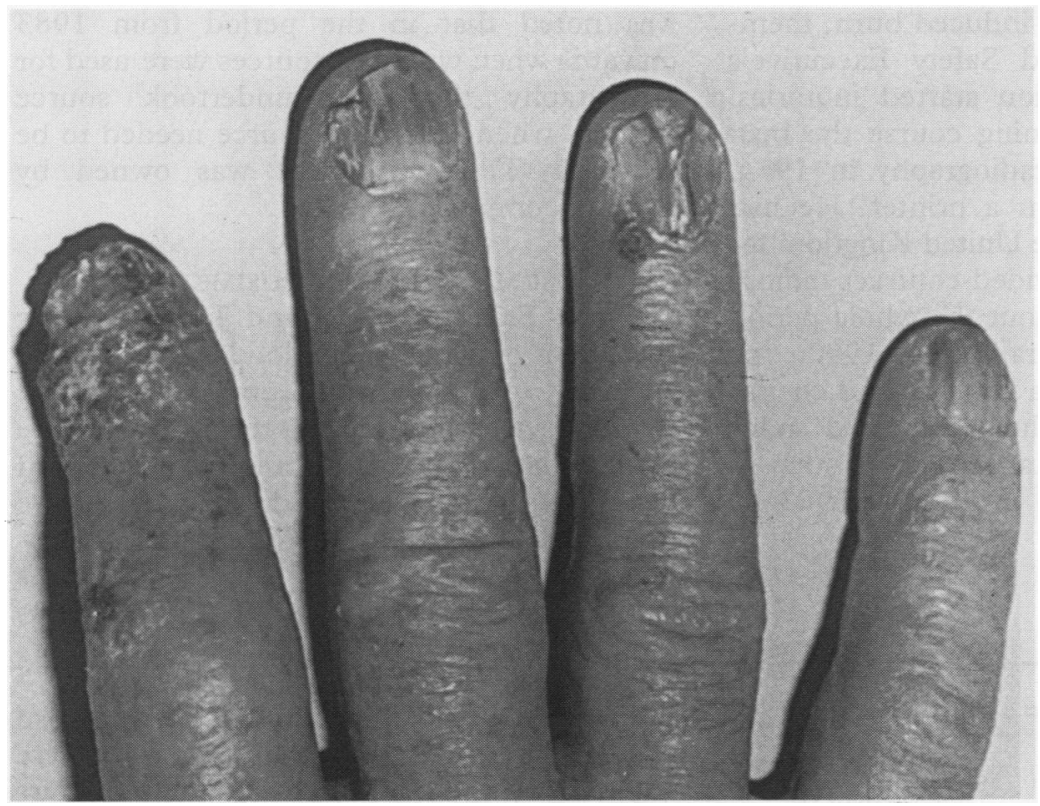

Figure 1 Fingers of the right hand in November 1989 showing ulceration of the index finger, scattered small keratoses, sclerosis with loss of wrinkling, and nails with ridging and ragged margins.
Serious occupationally related exposure to radiation of classified workers in the United Kingdom is rare. Good workplace standards, partly reflecting legislative encouragement, ${ }^{12}$ have helped to lessen risks although some specific problem areas remain. This paper describes the diagnosis, treatment, and dose estimates performed on an industrial radiographer who had a hand burn and subsequently developed a neoplasm from which he died. Both conditions were most probably caused by overexposure to ionising radiation.

\section{Case history}

The patient first experienced redness and swelling of his right index finger in $1984 . \mathrm{He}$ did not consult a doctor and the symptoms resolved without treatment. In May 1988 he consulted his general practitioner when the hand swelled again. The appearance was dermatitic with deformity of the nails for which he received griseofulvin but without benefit. The hand failed to heal and in October 1988 he was seen by a consultant dermatologist. The right index finger showed sclerosis and telangiectasia with three small crusted ulcers at the base, middle, and tip. The last ulcer involved the nail bed, with its partial destruction. The remaining nails of both hands were also abnormal with linear streaks and a ragged free margin. There were several keratotic lesions mainly affecting the right hand. In view of his professional use of hand held sources, radiation was assumed to be the cause. A skin biopsy from the distal part of the right index finger showed keratin thickening with parakeratosis and considerable acanthosis with irregular downgrowths of the basal layer. Individual cell keratinisation was seen here, but no atypia. These features are consistent with late radiation dermatitis. No definitive evidence of malignancy was seen. Flucloxacillin, topical gentamicin, and potassium permanganate baths helped for a while. The man then presented at a hospital outpatients' clinic in November 1989 with lesions on both hands; the right being considerably worse. The right index finger had deteriorated with ulceration over the terminal phalanx, such that its bone and the distal joint were exposed (fig 1). By February 1990 the finger was heavily infected. Terminalisation of the finger was unsuccessful and amputation was carried out with good results. The distal phalanx of the third finger was also removed.

Apart from a mild macrocytosis (mean corpuscular volume $99 \mathrm{fl}$ ) routine blood screen- 
ing was normal in February 1990. A blood specimen was also taken for chromosomal analysis, which confirmed that the patient had been excessively exposed to ionising radiation. He continued to be followed up as an outpatient and periodically further blood samples were sent for chromosomal analysis and routine screening. In early 1991 the nail changes and keratoses were still present in the left hand. Mild sclerosis was also slowly developing.

A blood examination in April 1991 showed changes that indicated myelodysplasia, haemoglobin $9.5 \mathrm{~g} / \mathrm{dl}$, white count 3.8 (blasts $0.2) \times 10^{9} / 1$, platelets $44 \times 10^{9} / 1$. This diagnosis was confirmed by bone marrow examination. This showed gross dyshaemopoietic activity. Myelopoiesis showed hypogranulation, pelger-huët forms and blasts at $20 \%$. Micromegakaryocytes were abundant and erythropoiesis was megaloblastic. A trephine biopsy showed intense myelofibrosis with hypercellular islands of abnormal haemopoietic activity.

This myelodysplastic state in transformation progressed to acute myeloid leukaemia by October 1991. Starting in April 1991 he was dependent on transfusions at a frequency of three units every three weeks. He was treated with chemotherapy, mitozantrone $10 \mathrm{mg} / \mathrm{m}^{2}$ on days 1 and 2 , and a cytosine $\left(1 \mathrm{~g} / \mathrm{m}^{2}\right)$ intravenous infusion twice daily on days 1-3 in March 1992. This treatment induced prolonged aplasia that was complicated by infection. At the time of his death in June 1992 aged 61 his marrow continued to show considerable hypocellularity.

At a post mortem examination a healthy molar tooth and some specimens of bone were removed for analysis by electron spin resonance.

\section{INVESTIGATION OF WORKPLACE AND EMPLOYMENT}

In March 1990, on learning that the patient had a possible radiation induced burn, members of the Health and Safety Executive's Field Operations Division started inquiries. After a one month training course the man had started industrial radiography in 1974 . Before this he had been a printer. He had worked exclusively in the United Kingdom for one employer, who provided contract radiography services. Throughout the whole period until he ended radiography in 1990, the man had been based at a large oil and chemicals complex where he performed nondestructive tests on metal structures such as pipe welds. From 1974 until early 1983 he

Unstable chromosomal aberrations found in blood lymphocytes

\begin{tabular}{llllll}
\hline $\begin{array}{l}\text { Date of } \\
\text { sample }\end{array}$ & $\begin{array}{l}\text { No of cells } \\
\text { scored }\end{array}$ & Dicentrics & $\begin{array}{l}\text { Centric } \\
\text { rings }\end{array}$ & $\begin{array}{l}\text { Excess } \\
\text { acentrics }\end{array}$ & $\begin{array}{l}\text { Dicentric yield I } \\
\text { cell (SE) }\end{array}$ \\
\hline 5 February 1990 & 2000 & 215 & 25 & 316 & $0 \cdot 108(0.008)$ \\
30 April 1990 & 500 & 35 & 6 & 68 & $0 \cdot 070(0.013)$ \\
17 July 1990 & 500 & 40 & 2 & 78 & $0.080(0.014)$ \\
13 December 1990 & 500 & 34 & 2 & 41 & $0 \cdot 068(0.013)$ \\
22 May 1991 & 500 & 35 & 3 & 49 & $0.070(0.013)$ \\
19 June 1991 & 500 & 21 & 0 & 27 & $0.043(0.010)$ \\
\hline
\end{tabular}

used iridium-192 sources ranging from 10 to $25 \mathrm{Ci}$ (400-1000 GBq) in torch type containers. In a typical working day he would perform about 30 radiographs. In 1983 the company stopped using these containers and radiography was then done with wind out remotely operated iridium-192 sources. Iridium-192 has a half-life of 74 days and a principal $\gamma$ ray emission of $320 \mathrm{keV}$.

An audit of the workplace in 1990 showed that the equipment was in good working order and documented procedures currently in use were safe. The man had unremarkable doses recorded on his routine personal monitors, which were generally monthly film badges until 1982, when the company changed to thermoluminescence dosemeters. For the period January 1986 to March 1988 he had been supplied with fortnightly badges. His lifetime total recorded dose was $104 \mathrm{mSv}$, none of which was notional, meaning that he had always returned his dosemeters for processing. He had only been issued with badges that were supposed to be pinned to the trunk and he invariably wore them at his waist. $\mathrm{He}$ had never been supplied with fingertip dosemeters. By comparison with the records of other long serving employees of the company, his recorded dose was lower than average.

The man had been examined medically in 1976 and 1982 under the terms of the 1969 Ionising Radiations (Sealed Sources) Regulations $^{3}$ and no problems had been identified. Subsequently, his health was surveyed according to the Ionising Radiations Regulations, $1985 .^{2}$ His health and employment records showed no abnormal periods of absence due to illness.

Interviews were conducted with the employer's Radiation Safety Officer, Radiological Protection Adviser, a number of radiographer colleagues of long standing, and the man himself. No explanation to account for untoward irradiation was forthcoming. It was noted that in the period from 1983 onwards when wind out sources were used for radiography the man undertook source changes when a decayed source needed to be replaced. This equipment was owned by another company.

\section{CHROMOSOMAL ANALYSIS; DOSIMETRY}

Between February 1990 and June 1991 six specimens of heparinised blood were taken for analysis of chromosomal damage. Lymphocyte metaphase preparations were made from 48 hour cultures by a standard technique. ${ }^{4}$ First in vitro division cells were examined for unstable chromosomal aberrations; dicentrics, centric rings, and excess acentric fragments (table).

\section{CHROMOSOMAL ANALYSIS; KARYOTYPING}

Bone marrow and peripheral blood were also taken in June 1991 for karyotyping. Both were cultured by standard methods for 24 hours without mitogenic stimulation. Slides were prepared and marrow and blood blast cells were karyotyped with Giemsa banding. 


\section{ELECTRON SPIN RESONANCE}

The distal phalanx of the right hand second finger, a piece of right humerus and a healthy molar tooth were removed at post mortem examination, and stripped of soft tissue by placing them in a colony of Dermestes maculatus beetles. The specimens were sent to the University of Osaka for electron spin resonance (ESR) dosimetry, ensuring that they were not subjected to $x$ rays in transit. Enamel from the tooth was carefully removed from the dentine by a diamond cutter microsaw.

The technique for ESR spectroscopy and converting the signals to absorbed dose has been described previously for atomic bomb survivors and residents close to the Chernobyl accident. ${ }^{56}$ In brief, the sample is placed in a static magnetic field and exposed to microwave radiation. The reflected microwaves are detected and, by sweeping through the magnetic field, a characteristic drop then a rise is seen in the microwave signal as a derivative absorption curve to the intensity of the magnetic field. This resonance is produced by a change in the spin state of unpaired electrons in the particular radical, $\mathrm{CO}_{2}^{-}$in hydroxyapatite, being examined. For tooth enamel and bone the measured carbonate radical resonates at a magnetic field of about $335 \mathrm{mT}$ in a microwave frequency of 9.5 GHz. If the specimen has been exposed to ionising radiation increased numbers of unpaired electrons are produced, which persist almost indefinitely, subject to remineralisation of the tissue during life. The signal intensity was calibrated against radiation dose with the additive dose method.

\section{Results and discussion}

The first problem with the right hand began about one year after the patient stopped working with torch radiographic sources (1984). The patient treated himself and did not seek medical advice or tell his employer. Four years later he sought treatment, so it is possible that the two episodes of swelling of the hand were unrelated and coincidental. The second

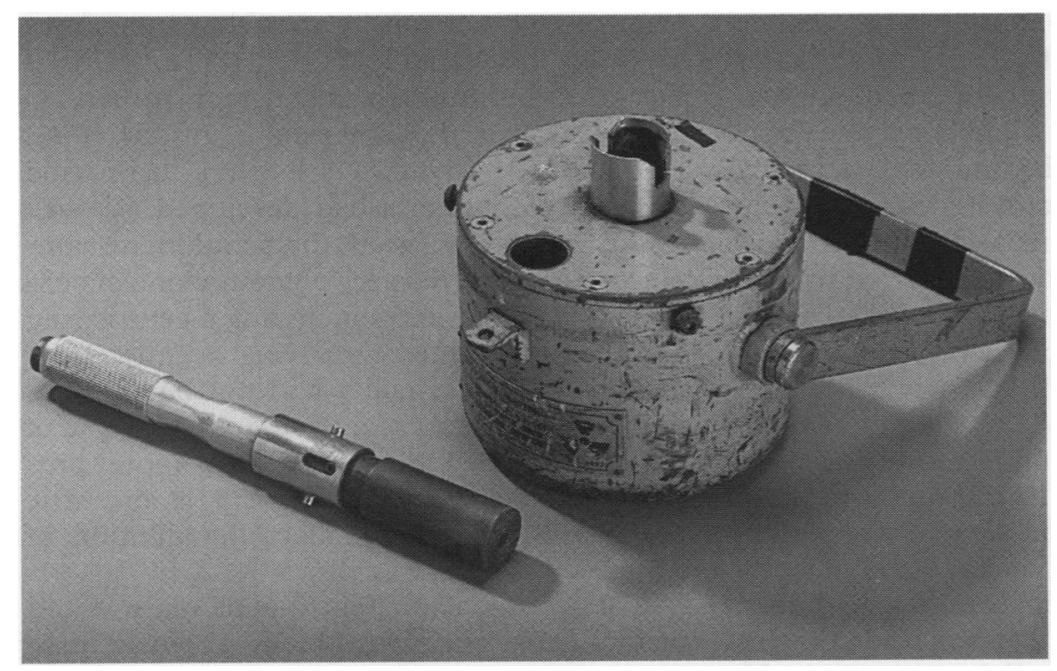

Figure 2 Vitosonics torch type of radiography source and its shielded carrying container. episode, which led to the ulceration, and was diagnosed as being induced by radiation, could still have been due to the torch sources. A latency of many years $(>10)$ may elapse between irradiation of the hand and development of ulceration or malignant degeneration of the skin, particularly if it is the cumulative effect of many exposures. ${ }^{78}$

Figure 2 shows a Vitosonics torch source container that when not in use is housed in the depleted uranium pot. A typical surface dose rate from this apparatus when not in use is about $1 \mathrm{mGy} \mathrm{h}^{-1}$. In use the torch is handled by the knurled end. The smooth and darker end contains the iridium-192 surrounded by a depleted uranium shield that is spring loaded. This source end is inserted into a lead "castle"; an applicator, which has been previously attached to the object being radiographed. The act of inserting the torch through a bayonet fitting, pushes back the uranium shield, and thereby exposes the source. Typical proper use would produce $10-20 \mathrm{mGy} / \mathrm{y}$ to the operator. Cases of burns related to the use of such instruments have been reported, however, they usually result in damage to the non-dominant hand; whereas this patient was right handed. These have arisen when the sources were inserted into applicators, before fixing the latter to the objects being radiographed. Another misuse that has been discovered is the practice of wedging the spring loaded shield back with, for example, a matchstick or sticky tape and dispensing with the use of the applicator. ${ }^{9}$ In this mode the radiographer's body would be exposed to $\gamma$ rays with the highest dose being received by the hand holding the torch. This malpractice saves time when a lot of radiographs are being carried out on piece work payments. Such misuse of sources is general knowledge among industrial radiographers, but it should be emphasised that in the case reported here, misuse was denied.

On changing over to use of wind out iridium-192 sources the man occasionally undertook source replacements for another company that owned radiographic equipment. These replacements occurred at the most twice yearly and the procedure took about 15 minutes. The maximum strength of source ever transferred was understood to be $22 \mathrm{Ci}$ $(814 \mathrm{GBq})$. In essence, the old source was wound from the source container into a hole along the central axis of a lead or steel shielding cylinder. A transverse slit in the cylinder enabled a hacksaw blade to be inserted so that the "pig tail" attachment could be severed. The detached source was then of a size such that it could be decanted into a torch type container for continued use as a small source of ionising radiation. (Before this transfer could be achieved the spent source previously in the torch type container had to be put back into a transport container for return to Amersham.) Done properly it was calculated that a source changeover from projection to torch container might entail a hand dose of $380 \mu \mathrm{Gy}$ and a whole body dose of $8 \mu \mathrm{Gy}$. Unattenuated radiation was able to emerge, 
however, from holes in the shielding and if the hand and upper body or head had been in such a beam possible doses of $140 \mathrm{mGy}$ and 3 mGy respectively could have been received. In such circumstances the waist, the normal site for wearing his personal dosemeter, and much of the lower body would be shielded by the shielding container. Procedures were in place to prevent exposure to the unattenuated radiation and there was no evidence that such exposure took place.

As no explanation for the severe lesion to the hand was given, the first firm corroboration that the patient had been significantly irradiated, was provided by the chromosomal analysis in February 1990. The incidence of aberrations (table) was considerably in excess of that expected from studies of control subjects exposed only to background radiation, namely about one dicentric, no rings, and three acentric fragments $/ 1000$ cells. ${ }^{4}$ Whereas acentric fragments can be caused by a variety of agents, a principal cause of dicentrics and rings in lymphocytes is ionising radiation. The only possibility other than radiation is a short list of cytotoxic drugs, which he had certainly not been prescribed. It was also apparent that the exposure was more complex than a single brief and very heavy irradiation of a hand. For such an event chromosomal analysis of circulating lymphocytes would be unlikely to detect aberrations much in excess of background. The proportion of the body's lymphocytes that would be within the radiation field would be considerably diluted by the circulation and the few that might be contained in the blood specimen would be unlikely to reach metaphase because of interphase death and mitotic delay.

Induction of dicentric aberrations has a highly reproducible relation with radiation dose, so that with reference to an in vitro calibration curve, it may be used as a biological dosemeter. ${ }^{4}$ Interpretation of the dicentrics in terms of dose requires some knowledge of the time interval between irradiation and blood sampling, information on whether exposure was brief or protracted, single or repeated events.

Some limited data from humans indicate that dicentric yields in lymphocytes decline with a half time of about three years and after a high ( $>1 \mathrm{~Gy}$ ) exposure, there is a more rapid fall off over the first year. ${ }^{4}$ There may be some evidence of this from the earlier data in the table, but it is not clear cut. Exposures lasting for $>30$ minutes result in a lower aberration yield than if the same dose is received briefly. Also, intermittent exposures, even if each fraction is brief, will similarly result in a lower aberration yield, than if the whole dose is given at one time. ${ }^{4}$

With no information on the time course of exposure, the results (215 dicentrics in 2000 cells) from the first blood sample were interpreted as indicating an average whole body dose of around $1 \mathrm{~Gy}$ if the exposure had been received as a single brief event at some time in the few months before February 1990. If, however, exposure had been protracted or intermittent during those months, the estimate of dose would rise to about $5 \mathrm{~Gy}$. If it was assumed that the hand lesion, including the original swelling in 1984, was connected with more general irradiations that caused the aberrations seen in the lymphocytes, then much older exposure needs to be considered. A single brief exposure 10 years before blood sampling would lead to an estimate of about 4 Gy although it is difficult to envisage this occurring without the patient having early symptoms of radiation sickness. Many intermittent exposures, each being either brief or protracted, spanning the period 1974 to 1983 , when he worked with the torch sources, would lead to a much higher estimate of possibly several 10 s Gy.

An indication that at least some of his exposure was not recent was that as well as the aberrations noted in the table each specimen also contained cells with dicentrics or rings that were missing the usually accompanying acentric fragment. In the first specimen, which was taken while he was haematologically normal, there were an additional 49 dicentrics and five ring "incomplete" aberrations noted in lymphocytes that had undergone only one in vitro cell cycle. This implies that in vivo division had occurred at which fragments were lost by non-disjunction. As peripheral $T$ lymphocytes rarely divide and have long life spans this is suggestive of old exposure but the findings can not be used quantitatively. ${ }^{10}$

The distributions of dicentrics among the scored cells were significantly overdispersed with respect to the Poisson distribution that would characterise a uniform whole body irradiation. ${ }^{4}$ For the first specimen the ratio of variance to mean was $1 \cdot 24, \mathrm{u}=7 \cdot 5$, which provides evidence of non-uniformity and would correspond to about half the body having been irradiated. It is difficult to envisage how such a result could have come from repeated hand exposure where perhaps only $1 \%$ of the lymphocytes were exposed on each occasion. The electron spin resonance analysis, done two years later, confirmed that there had indeed been exposure to more than just the hands.

In the table it can be seen that from April 1990 to May 1991 the observed yield of dicentric aberrations was constant. It then fell considerably in the final sample in June 1991. The last two samples are from the period when myelodysplasia had developed. As well as the aberrations listed, the penultimate sample also contained a very obvious clone of cells with 44 chromosomes including a centric ring but without an accompanying acentric fragment. This abnormality had not been found in the previous samples. In the final sample of June 1991 the clone was even more pronounced and the reduced yield of dicentric aberrations may well reflect the dilution of lymphocytes by blast cells.

Chromosomal analysis of bone marrow and unstimulated peripheral blood taken in June 1991 showed the following karyotype in all cells examined: 
44,XY,del(5)(q13q33),-7,derdel(7), $-12, \operatorname{der}(12), \operatorname{der}(17 \mathrm{p}),-20,+$ ring

This is similar to blast cell karyotypes found in secondary myelodysplasia arising in patients previously treated with genotoxic agents for cancer. ${ }^{11}$ Of patients with secondary myelodysplasia $55-84 \%$ progress to acute myeloid leukaemia and their median survival is $<1$ year. Clonal abnormalities have been reported in $76-97 \%$ of cases, with -7 and del(5) seen in up to $90 \%$, which are considered to be characteristic. Other changes associated with secondary myelodysplasia or acute myeloid leukaemia include rearrangements affecting $12 \mathrm{p}$ and $17 \mathrm{p}$. Unstable configurations such as rings and dicentrics are also characteristic. Secondary myelodysplasia or acute myeloid leukaemia have primarily been associated with exposure to alkylating agents and more recently epidophyllotoxin, but irradiation to a large volume of bone marrow also increases the risk of leukaemia. It has been suggested that $5 \mathrm{q}^{-}$is particularly associated with radiotherapy whereas -7 is more characteristic of chemotherapy. The median latency of secondary myelodysplasia or acute myeloid leukaemia related to treatment is 4-5 years but with a range of $<1->25$ years. ${ }^{111213}$

Data from Pedersen-Bjergaard et al suggest that there may be differences between those patients who develop secondary myelodysplasia or acute myeloid leukaemia 30-60 months after treatment and those who develop it either before 30 months or after 60 months. ${ }^{14}$ In the group with a latency of $<30$ months, patients most often present with myelodysplasia rather than acute myeloid leukaemia $(88 \%$ $v 47 \%)$, have an abnormal karyotype $(100 \% v$ $66 \%$ ) with a hypodiploid modal number $(100 \% v 40 \%)$ and combined B and C group chromosome changes $(50 \% v 13 \%)$. It is interesting that this patient presented with myelodysplasia and a hypodiploid karyotype with both $B$ and $C$ group chromosome abnormalities.

The tooth and bone specimens examined post mortem by ESR provided further evidence that the man had been excessively irradiated. The value derived from the tooth was $14.5(2.0) \mathrm{Gy}$. This is possibly the most reliable evidence in the sense that once a tooth is formed its enamel is never renewed and so the dose derived from it reflects almost the whole of the person's life time exposure. As this man died in his early 60 s one would expect the tooth to have received $50-100 \mathrm{mGy}$ from natural background radiation and, unless he had received an exceptional amount of dental radiography, about another $100 \mathrm{mGy}$ from this source. The values obtained from the bone specimens were $14.7 \mathrm{~Gy}$ for the finger digit and $7.0 \mathrm{~Gy}$ for the humerus. It should be remembered that unlike dental enamel the mineral material of bone is subject to renewal throughout life, and hence loss of signal. Nevertheless these values, which represent fixed sites in the body, complement the average dose estimate obtained from the lymphocytes, and confirm that the patient had received very high exposure that was not confined just to the hands. The magnitude of the estimated doses is considerably above the threshold for acute radiation sickness and thus provides further confirmation of the postulate that he had been exposed on many occasions rather than as a single event.

A computer program (SPIDER-1 ${ }^{15}$ ) that considers radiation related risks and probability of causation of cancer has been developed at the National Radiological Protection Board. It follows a BEIR-V type risk projection model, ${ }^{16}$ modified to be specific to the population of the United Kingdom, ${ }^{17}$ by using United Kingdom Office of Population Census and Surveys cancer statistics and life tables for 1985.

The algorithms were applied to the case of a man, dying aged 61, after an average whole body exposure of $10 \mathrm{~Gy}$, received at a constant rate spanning 10 years from the age of 40-49. To allow for the time course of irradiation a dose and dose rate effectiveness factor of 2 was assumed. ${ }^{17}$ With these assumptions the annual risk of fatal leukaemia in the age range $60-65$ years was $0 \cdot 22 \%$ compared with an annual background risk of $0.013 \%$. The resultant probability of causation is

$$
\frac{0 \cdot 22}{0.22+0.013}=0.94 \text {. }
$$

This seems fairly conclusive although it must be remembered that this is a probability rather than a proof of causality. Apart from the underlying uncertainties of total dose and its time course the main limitation of this calculation is that epidemiological and demographic data are applied to the individual. It assumes that the individual is of average susceptibility to cancer. Despite this the probability of causation approach ${ }^{18}$ seems to be a logical and reasonable procedure for assessing the presumption of malignancy induced by radiation.

\section{Conclusion}

Chromosomal and electron spin resonance analyses have provided firm evidence of serious overexposure to penetrating radiation. Although all the evidence suggests that this was due to work with industrial $\gamma$ sources it has not been possible to establish how the exposure occurred. The right hand intermittently received an immense dose; possibly 100 Gy. This resulted in chronic dermatitis that progressed to ulceration and required partial amputation. Much, perhaps all, of the body was also exposed to a substantial averaged dose, likely to be in excess of $10 \mathrm{~Gy}$, which was received intermittently probably spanning several years. It is highly probable that this caused his fatal myelodysplasia, which was characterised by blast cells of which the morphology, karyotypes, and progression to acute myeloid leukaemia bore a striking resemblance to those reported in patients who develop this condition some time after a successful course of radio and chemotherapy for cancer. 
We thank Mr J D Robb of the National Radiological Protection Board for carrying out the probability of causation calculation.

1 Health and Safety at Work etc Act, 1974. London: HMSO, 1974.

2 The Ionising Radiations Regulations, 1985. London: HMSO, 1985. (Statutory Instrument No 1333.)

3 Ionising Radiations (Sealed Sources) Regulations, 1969. London: HMSO, 1969. (Statutory Instrument No 808.)

4 Biological dosimetry: chromosomal aberration analysis for dose assessment. Vienna: International Atomic Energy Agency, 1986. (Technical Report No 260.)

5 Ishii $H$, Ikeya $M$. An electron spin resonance system for in vivo human tooth dosimetry. Fapanese fournal of Applied Physics 1990;29:871-5.

6 Ikeya $M$. New applications of electron spin resonance, dating, dosimetry and microscopy. Singapore: World Scientific, 1993.

7 Tilkorn H, Drepper H, Ehring F. Indications for the treatment by plastic surgery of the effects of radiation and radiolesions on the skin. $B r f$ Radiol 1986;(suppl 19): 131-4.

8 Hartwell S, Huger W, Picknell K. Radiation dermatitis and radiogenic neoplasms of the hands. Ann Surg 1964;160:828-34.

9 Mullarkey DT. Radiation overexposure of an industrial radiographer. Radiological Protection Bulletin 1974;6: 16-7.

10 Lloyd DC, Purrott RJ, Dolphin GW. Chromosome aberration dosimetry in a case of overexposure to radiation. Nature 1973;241:69-70.
11 Levine EG, Bloomfield CD. Leukaemia and myelodysplastic syndromes secondary to drug, radiation and enviplastic syndromes secondary to drug, radiation and

12 Johansson B, Mertens F, Heim S, Kristoffersson U, Mitelman F. Cytogenetics of secondary myelodysplasia (sMDS) and acute nonlymphocytic leukaemia (sANLL). Eur F Haematol 1991;47:17-27.

13 Pedersen-Bjergaard J. Radiotherapy-and chemotherapy -induced myelodysplasia and acute myeloid leukaemia A review. Leuk Res 1992;16:61-5.

14 Pedersen-Bjergaard J, Philip P, Mortersen BT, et al. Acute nonlymphocytic leukaemia, preleukaemia and acute myeloproliferative syndrome secondary to treatment of other malignant diseases. Clinical and cycor the mics and results of in vitro culture of bone marow and HI A typing, Blood 1981;57:712-23.

15 Stokell PJ, Robb ID, Crick MJ, Muirhead CR. SPIDER-1: sofivare for evaluating the detriment associated with radia sofivare for evaluating the detriment associated with radiation exposure. Chilton, Oxfordshire: National Radiological Protection Board 1993;Report R-261.

16 BEIR-V. Health effects of exposure to low levels of ionising radiation. Fifth report of the Committee on the Biological Effects of Ionising Radiation. Washington: Nationa Academy of Sciences, National Research Council, 1990.

17 Muirhead CR, Cox R, Stather JW, MacGibbon BH, Edwards AA, Haylock RGE. Estimates of late radiation risks to the UK population. Documents of the NRPB. Chilton, Oxfordshire: National Radiological Protection Board, 1993. (Vol 4:15-157.)

18 National Council for Radiation Protection. The probability that a particular malignancy may have been caused by a that a particular malignancy may have been caused by a
specific irradiation. Bethesda: NCRP, 1992. (Statement Specific

\section{Correspondence and editorials}

Occupational and Environmental Medicine welcomes correspondence relating to any of the material appearing in the journal. Results from preliminary or small scale studies may also be published in the correspondence column if this seems appropriate. Letters should be not more than 500 words in length and contain a minimum of references. Tables and figures should be kept to an absolute minimum. Letters are accepted on the understanding that they may be subject to editorial revision and shortening.

The journal also publishes editorials which are normally specially commissioned. The Editor welcomes suggestions regarding suitable topics; those wishing to submit an editorial, however, should do so only after discussion with the Editor. 